\title{
VEREENIGING VOOR DE STATISTIEK IN NEOERLAND.
}

\author{
TOESPRAAK VAN DEN VOORZITTER.
}

In de jaarlijksche Algemeene Vergadering den 14en April te Rotterdam gehouden, was ter bespreking de zaak der WerkliedenPensioenen aan de orde gesteld, in verband met de werkzaamheden der Commissie welke eerlang omtrent de oprichting van een Algrmeen Pensioenfonds voor werklieden zal rapporteeren. Het onderwerp werd ingeleid door Dr. J. Th. Mouton van 's Gravenhage, die verscheidene punten van uitvoering besprak, en mededeelingen deed aangaande het stelsel der Commissie, welke thans met haar werk nagenoeg gereed is. Aan het debat werd voorts deelgenomen door de HH.: A. S. van Reesema, - die voor deze pensioenen het, ook door de Esonomist voorgestane stelsel van ansluiting aan bestaande soliede maatschappijen aanbeval, - benevens door de HH. v. Kempen, Feldt en prof. Greeven, die aan een nieuw opterichten speciaal fonds de voorkeur gaven. Het onderwerp en bepaaldelijk dit geschilpunt is aan onze lezers bekend door vorige artikelen in de Economist, van den Hr. Samot.

Wij verwijzen voor het thans gehouden debat, naar de Verslagen daarvan in de Dagbladen van 15 April voorkomende; terwijl het volledig stenografisch verslag als gewoonlijk in het Jaarboekje der Vereeniging zal verschijuen.

In afwachting daarvan doen wij hier de toespraak volgen van den Voorzitter bij de opening der Vergadering gehouden, waarin een en auder over de werkzaamheden der Vereeniging werd medegedeeld, en tevens eenige punten in betrekking tot onze officieele Statistiek werden besproken.

„Bij het voortzetten onzer werkzaamheden" zeide de Spr. „rust op mij in de eerste plaats de gewone verplichting om hen te her- 
denken, die ons zijn ontvallen. Indedaad cene treffende lijjst. Hadden wij verleden jaar het verlies te betreuren der H.H. Freseman Vietor, Lenting, Idzerda, Feith, Dr. van den Boogaard, de Bruijn Kops en Schiff te Batavia, Goudsmit en de Clereq, - die lijst werd in het nu afgeloopen dienstjaar weder vergroot door het verlies der H.H. F. W. C. Krecke te Utrecht, Dr. Büchner, Jhr. Mr. B. de Bosch Kemper, Jhr. Mr. C. J. A. den Tex, Ch. Muller, A. van Otterloo te Amsterdam, Mr. J. A. Jolles en A. J. H. van den Toom te 's Gravenhage, J. P. A. Thiel te Vierlingbeek en Mr. G. Mees Az. te Rotterdam.

$\mathrm{Zij}$ allen hebben eene eervolle plaats vervuld: in de wetenschap, in de regeering, bij het onderwijs, of in de magistratuur. En mochten slechts enkele humner geregeld aan onzen eigenlijken arbeid deelnemen, toch brengen wij een dankbare hulde aan hun onvermoeid streven op den weg van vooruitgang, een streven dat met het onze zamenvalt, en dat ons het recht geeft, om bij humne nagedachtenis te zeggen, dat humne werken hen volgen!

Weinig dacht ik, toen ik dezer dagen de lijst onzer verliezen opmaakte, dat ik daarbij nog den naam zoude hebben te voegen van Dr. Steijn Parvé, inspecteur van het middelbaar onderwijs, die in deze week plotseling werd weggerukt en wiens ter aardebestelling hoden plaats vindt, na een leven, werkzaam als van slechts weinigen.

Velen uwer zullen met mij het voorrecht gehad hebben hem van nabij te kennen; zullen kunnen getuigen van zijne meer dan gewone arbeidskracht, ran zijne geheele toewijding an de zaak die hem was opgedragen, en waaraan hij het grootste deel van zijn ambtelijk leven heeft dienstbaar gemaakt. Nog weinige dagen geleden had ik hem eenige vrij uitvoerige inlichtingen te vragen in verband met de werkzaamheden onzer vereeniging. En bet trof mij dat, reeds twee à drie dagen daarna, tot mij $\mathrm{kwam}$ een uitroerig schrijven, al de punten resumeerende, benevens een groot aantal cijfers en opgaveu, die de duidelijke blijken droegen van onderzoek en besteedde moeite. Zoo was de man geheel. Wat hij te doen had, deed hij dadelijk en terdege En het is mij gebleken dat hij toen toch reeds moet geweest zijn onder den neerdrukkenden invloed der ziekte, die hem, helaas! zoo spoedig daarop ten grave heeft gesleept. Welligt waren deze werkzaamheden ten ouzen behoeve, de laatste die hij verricht heeft. Moge zijn vosrbeeld, evenals dat van den Tex en andere krachtige persoonlijkheder, ous opwekken om, elk in onzen kring, 
voortdurend tot leus te blijven houden: „Te werken terwijl het dag is!"

Mijne heeren, straks in de huishoudelijke bijeenkomst heeft deze vergadering den opvolger in het bestuur benoemd van uwen tegenwoordigen voorzitter die, volgens het in 1881 door ons ingevoerd beginsel van periodieke aftreding, thans daarvoor aan de beurt was. Het is nu ruim 30 jaren lang dat ik - ik mag zeggen onafgebroken - deel heb uitgemaakt van dat bestuur. En wanneer ik dat herdenk. treft mij het verschil tusschen het gebied van statistiek, dat wij thans kunnen overzien en bewerken, met het toenmalige, toen ik voor het eerst door den hooggeachten oprichter van deze vereeniging, de Bosch Kemper, en den hooggeachten Ackersdijk tot medebestuurder der vereeniging, of, zooals het toen heette, tot mede-redacteur van het Jaarboekje werd benoemd. Wanneer gij, mijne heeren, de eerste deelen daarvan inziet, zult gij bevinlen, dat b. v. omtrent den werkkring der Nederlandsche Bank, het gewichtig onderwerp dat thans zalk eene leerzame plaats inneemt, in 1851 de toenmalige secretaris van de Ned. Bank, spoedig daarop president, de heer Mees, mededeelde: 10. de discouto-rente; 20. de beleening-rente, (twee posten, die trouwens weinig variëerden); 3o. het bedrag van het reservefonds, en 40. wat het dividend was geweest. Dat was alles wat hij mocht mededeelen, de rest was Bankgeheim. En daartegenover wijs ik nu op de hoogst belangrijke en uitvoerige overzichten, welke door onzen geachten medewerker, den heer Baert, o. a. verleden jaar en vroeger reeds meermalen zijn geleverd; overzichten die al de operatien van de Bank in de bijzonderheden nagaan. En dan heb ik zeker niet meer noodig om te doen gevoelen wat wij op dit punt gevorderd zijn.

Er zijn echter nog andere onderwerpen waarbij een groot verschil is waar te nemen, en waarbij de beoefenaar van statistiek, bij vergelijking der twee tijdstippen, zich inderdaad over vooruitgang mag verblijden. Omstreeks 185̃2, tijdens de invocring van de Gemeentewet, heb ik een werkje gesehreven over Indirecle beluslingen, als middel van plaatselijke inkomst; ik had daarbij de gemeente-accijnsen, die toen zulk eene onrustbarende hoogte bereikt hadden, voor het eerst tot onderwerp van studie gemaakt. Daarbij waren statistieken en begrootingstukken noodig, die toenmaals begraven lagen in de secretarien der gemeenten. En nu staat mij nog levendig voor den geest, hue bedenkelijk leden van 
gemeentebesturen en Gedeputeerde Staten mij aanzagen, en hoe ik van meer dan eenen kant den welgemeenden raad kreeg om zulke zaken als de ophrengst ran het gemaal, het geslacht enz. toch niet to doen drukken! Dat hoorde bij de hecren te huis, niet bij het publiek. Gelukkig was men spoedig op een gebeel anderen weg, en reeds in 1855 ware nagenoeg alle gemeente-accijnsen voor de kracht van de pululieke opinie liezweken.

En toch, mijno Heeren, - - valt het aan de enne zijde niet te ontkennen, dat de statistiek in die jaren ran overgang eene gewichtige plaats vervuld heeft, en een niet onbelangrijke factor was bij onze economische hervorming, - men zal terens moeten erkennen dat de oude tocstand, technisch gesproken, voor de statistiek cigenlijk meer materiaal leverde, dan de tegenwoordige. Zoo gaven de gemeente-accijnsen de gelegenheid om in afgesloten kringen de consumtie van jaar tot jaar met volkomen juistheid na te gaan; dat niddel ontbreekt thans geheel. Dat is trouwens cen onvermijdelijk gevolg van de rrijheid. Het spreekt b. v. van zelf dat het voor een land dat geheelen vrijhandel heeft, en mitsdien geen in- of uitwoerrechten kent, vrij wat moeilijker is on den in- en uitwoer in bijzonderheden te kemnen, dan voor een land, dat leeft onder het strenge systeem van een uitvoerig douane tarief.

Hetzelfde is het geval met de verbruiksbelastingen. Zoo kon men bijv. tijdens de gemaalbelasting, aan het Departement van Financien van jaar tot jaar, met juistheid nagaan wat per hoofd der bevolking aan tarwe geconsumeerd was. Dat was een statistisch voordeel dat thans ontbreekt, en dat, toen vooral, veel waard was. Immers, toen daardoor werd aangetoond dat in de 20 jaren na 1 S33 die tarwe-consumtie per hoofd der bevolking berekend, in alle provincien, zonder uilzondering, telkens achteruitging, terwijl de consumtie der minder belaste rogge in dezelfde verhouding toenam, had men van zelve een sprekend argument, om het onhoudbare van den toenmaligen toestand aan te toonen, zoowel economisch als fiscaal. Dergelijke middelen om alle deelen van het volksverbruik met juistheid te kunnen nagaan, staan ons thans niet meer ten dienste. Maar het is toch bemoedigend te zien dat onze landbouwstatistiek, - die in den laatsten tijd nog zooveel is verbeterd - in verband met onze in- en uitvoerstaten, ons de middelen an de hand geeft om te zien, dat de tarweconsumtie, na de afschaffing der gemaalbelasting, voortdurend is toegenomen, en wel zoo, dat zij thans het dubbel à driedulsbel 
hedraagt per hoofd der bevolking berekend, van hetgeen zij was in 1855 , tijdens de belasting.

En zoo vindt men bij de beoefening van onze wetenschap veel dat ons moet aansporen om met vereenigde krachten het publiek te gewennen aan het gebruik van statistiek, als onmishaar om den economischen volkstoestand goerl te bëoordeclen.

Thans een paar opmerkingen naar aanleiding van hetgeen gedurende het laatste jaar ann statistiek werd geleverd, zoowel 10. door de regeering, in de reeks harer gewone publicatien, als 20. door onze vereeniging.

Ten aauzien van de regeeringsstatistieken 1882 (waarvan de gewone lijst is opgenomen in ons Jaarboekje) wijs ik in de eerste plaats op die val het Grondcrediet. Dit tafereel onzer hypothecaire schuld erlangt te meer waarde, nu de bij de wet voorgeschreven vernieuwing voor het eerst de gelegenheid aanbood om een juist overzicht te hebben van den stand der hypothecaire schuld op een gegeven tijdstip. Uit die statistiek blijkt hoeveel jaarlijks werd ingeschreven, doorgehaald, en vernieunod ingeschreven. Dit nagaande komt men tot de slotsom, dat de gansche schuld op den grond en andere onroerende goederen in Nederland rustende, in 1880 bedroeg 809 millioen guldens Dit cijfer verkrijgt men door rekening te houden met de gedeeltelijke vernieuwingen in 1879 en 1880 . Stelt men nu dat sedert kan zijn bijgekomen, aan eerste inschrijvingen, voor 40 à 50 millioen per jaar, dan kornt men tot de conclusie dat de geheele hypothecaire schuld thans ongeveer 900 millioen zal bedragen.

Bij de vele bijzonderheden die verder worden opgegeven, mag hier niet onvermeld blijven dat de bewerking dezer statistiek voor het gronderediet grootendeels te danken is an de ijverige pogingen van ons vroeger geacht medelid, den heer Bachiene, welke bij gelegenheid van een der congressen voor de Statistiek, toen dit onderwerp besproken werd en men wensehte dat de Regeeringen dienaangaande cen onderzoek zouden instelleu, dit punt bij onze Regeering ter sprake, en gedeeltelijk door eigen arbeid tot stand heeft gebracht. Wel ware het te wenschen, dat aan andere onderwerpen door statistische congressen aall de aandacht der Regeeringen aaubevolen, evenzeer de hand ware gehoudeu als door den heer Bachiene ten opzichte van dit onderwerp is gedaan.

Eene andere van de in den laatsten tijd uitgekomen statistieken, die van het Stoomwezen, is eveneens van niet gering belang. Men zal zich herinneren hoe gedurende eene lange reeks van jaren die statistieken veel te wenschen overlieten. Men vond vroeger 
dienaangaande, om de drie of vier jaren, sporalische opgaven in het een of ander nieuwsblad. Die waren lan wol afkomstig van het toezicht op de stoomwerktuigen, doch er was niet voldoende gelilassificeerd, en het geheel was zeer onvolledig. Met dankbaarheid mag ik herinneren dat sedert 1877 inderdaad zeer goede, volledige en systematische overzichton daarvan jaarlijks verschijnen. De verdecling van de stoomwerktuigen in die voor de waterbemaling, voor de fabrieken en andere inrichtingen, voor landbouw, voor schepen, wordt goed gevolgrd. De locomotieven van de spoorweren zijn er buiten, zijnde die aan een afzonderlijk onderzoek onderworpen, maar de tramlocomolieven zijn er onder begrepen.

Uit die statistiek blijkt nu vooreerst het zeer verblijdend feit dat onze stoomindustrie (nl. het inwerking brengen van niouwe stoommachines) in het algemeen sterk vooruitgaat, - de vermeerdering is treffend, zijnde het aantal der in gobruik zijnde stoomketels van 1877 tot $18 \mathrm{2} 2$ van 4,753 tot 6,413 vermeerderd, maar ten andere zien wij ook dat onze werktuigfabrieken meer en meer kumen concurreeren met de buiteulandsche. Immers de opgaven onderscheiden het bimen- en buitenlandsch fabriekaat, en wii zien dat het eerste in grooter mate is toegenomen dan het buitenlandsche. Terwijl toch het buitenlandsche vall 18771882 vermeerderde van 2,156 tot 2,785 , nam het binnenlandsche toe van 2,597 tot 3,628 , hetgeen dus voor deze laatste een beduidende toeneming aanduidt. Dezelfde onderscheiding wordt ook gegeven voor de verschillende soorten van stoomwerktuigen, (en zoo zien wij dat o. a. de ketels voor de tramlocomotieven nog alleu uitsluitend door het buitenland worden geleverd.)

Alles te zamen genomen, is het indedaad bemoedigend dat deze tak van industrie, dio met zoovele bezwaren heeft te worstelen gehad, in ons stelsel van vrijhcid toch is kunnen opkomen, en voortgaat met zich te ontwikkelen Het is trouwens hetzelfile verschijnsel, dat zich, na vele jaren van tobben en moeijolijkheden, ten aanzien van onzen scheepsbouw heeft voorgedaan, daar toch het bouwen ran jjzeren schepen, ja zelfs van groote ijzeren stoomliooten, op de inrichtingeu van Amsterdam, Rotterdam, Vlissingen en Delfshaven eindelijk eene betero toelromst schijnt te gemoet to gaan.

Wanneer ik wijjs op hetgeen in onze Regeerings-statistiek geleverd wordt, mag ik niet nalaten de aandacht te vestigen op de vorbeteringen die daarin, naar mijn beseheiden me.ning, konden aangebracht worden. 
Zoo meen ik dat dikwijls meer spoed met de uitgave kon gemaakt worden. Bij onze maandelijksche handelsstatistick b. v. treft het, dat wij eerst aan het einde van Maart de statistiek van December des vorigen jaars ontvangen, terwijl iedereen die de Engelsche tijdschriften, b v. the Economist, leest, weet dat men daarin in het midrien van iedere maand do officieele statistiek van het jaar, loopende tot den eersten dierzelfde maand, opgenomen en besproken vindt

Wanneer dit nu mogelijk is in Engeland, waar de opgaven over cen zooveel grooter handelsomvang en meer havenstaten loopen dan bij ons $\left({ }^{*}\right)$ dan geloof ik dat met eenigen goeden wil het verschijnen van onze statistiek spoediger zou kunnen plaats hebhen. Bij andere statisticken, als bij het armwezen, is die trage versehijning evenzeer optemerken. Soms moct er een geheel jaar verloopen eer men een volledig overzicht over het voorafgaande jaar verkrijgt, waardoor de belangstelling en de onmiddellijke praktische waarde verminderen, en slechts eene zekere historische waarde overblijft.

Een ander punt, waaromtrent de Regeeringsstatistiek soms te wenschen overlaat, hetreft de gelijkvornigheid. Het is wenschelijk dat alles wat tabellarisch van het eene jaar op het andere kan geleverd worden, ook zoodanig wordt ingericht, zóó dat vaste good ingedeelde, en goed aansluitende staten cle grondslag blijven.

Bepaaldelijk zijn het de verslagen van het Departement van Binnenlandsche zaken uitgaande, die in dit opzigt te wenschen overlaten. De statistiek wordt daar $m$. i. nog te veel in den tekst gebragt en als 't ware "verhaald". - Dat is niet bevorderlijk voor een goed gebruik. Het gebeurt niet zelden dat de in het overzicht genoemde eijfers niet volkomen aansluiten aan die van voorafgaande verslagen, hetzij er wat is bijgevoegd of weggelaten. Het verschil wordt dan soms in den tekst toegelicht, maar de raadpleging van dergelijke statistieken gaat met moeite gepaard, die konde vermeden worden indien men zich aan goed doordachte tabellen hield, wier nauwkeurige invulling goed gecontroleerd werd.

Over het algemeen voldoen de publicatien van Binnenlandsche Zaken niet zoo aan de eischen eener goede statistiek, als b. v. bij Financien uit den aard der tabellen vau zelve voortvloeit, en bij

(*) Zoo vind ik dat bet Stativitical abstract of the Dnited Stutes, 165 pas. dut thans voor inj ligt, vau 5 l'ebr. 1883 dagteekent, Washingtou, en dat daariu de cijfers van deu haudel, ook die met de verschilleule rijkeu atzouderlijk, vourkomen over het volle jaar 3882 !

RED. 
Waterstaat door doelmatige inrichting der statistieken van scheepvaart, spoorwegen en stoomwezen het geval is.

Een ander punt, ook onder het Departement van Binnenlandsche Zaken ressorteerende, en waarin $\mathbf{m}$. j. verhetering te brengen is, hetreft de Provinciale Verslagen. Wanneer men uit deze verslagen een geheel roor het Rijk wil zamenstellon, bijv. aangaande de geldmiddelen van de gemeenten, zal men zien, dat men wel een eind weg komt, doch men zal bịj sommige provinciën stuiten, cenvoudig omdat deze niet nelijkrormig met de andere zijn opgemaakt. Toch meen ik dat gelijkvormigheid van de provinciale verslagen in de meening van den wetgever gelegen heeft, toen hij die verslagen verordende.

Ik geloof daarom dat de hand moet gehouden worden aan de opvolging van door het Dept. van Binnenl. Zaken voorgeschreven model-staten.

De vrijheid van Ged. Staten, om buitendien alle bijzonderheden en beschouwingen mede te der!en die zij in het belang der provineie noodig oordeelen, zon natuurlijk onverkort blijven bestaan, doch om uit die kostbare en vaak belangrijke stukken jaarlijks een systematisch overzicht voor het Rijk te kunnen opmaken, is de tegenwoordige inrichting onvoldoende, ' $t$ geen toch met eenig overleg en goede voorschriften zoudn te verhelpen zijn.

De officieele statistieken der Departementen ran Financien en van Waterstaat, Handel en Nijverheid, hebben sedert 1877 groote vorderingen gemaakt, en daaraan wordt goed de hand gehouden. Nogthans worden in de uitvoerige en niet genoeg te waardeeren statistiek der geldmiddelen nog eenige leemten aangetroffen. Zoo vestig ik uwe aandacht op eene tabel omtrent de prrsoneel belasting, in vroeger jaren nu en dan gegeven. Daarin heeft men eene zeer uitvoerige klassificatie van de woonhuizen rolgens de huurwaarde, zoowel in elk der provincien afzonderlijk, als in de klassen der gemeenten naar gelang der bevolking Die tabel geeft een middel aan om ten aanzien der woningen, en daardoor indi. rectelijk eenigermate van de inkomsten, cen overzicht te verkrijgen, dat vooral een nuttig element is, nu de herziening van het gemeentelijk belastingwezen weder aan de orde is. En toch ontbreekt die tabel sedert eenige jaren, terwijl hare periodieke verschijning ter vergelijking zeer gewenseht zoude zijn.

Mijne Heeren, wij zijn geene Adviseurs der Regeering, doch zoolang ons desideratum, een Centraal Bureau niet is opgericlit, dat tot taak zoude heblen, in de offcieele statistiek de zoo ge- 
wenschte verbeteringen aantebrengen - meen ik dat het op onzen weg ligt, om, bopen wij met goed gevolg, de Regeering op bestaande leemten te verwijzen.

En dit brengt mij van zelf tot een speciaal punt, waaromtrent het Bestuur straks een voorstel zal doen. Ik bedoel de inrichting onzer Handelsstatistiek. Het is $\mathbf{u}$ bekend, mijne Heeren, dat deze wat juistbeid aangaat, te wenschen overlaat. Wij kunnen ons echter trousten met de gedachte dat dezelfde klacht in meest alle Rijken gehoord wordt.

Gedeeltelijk is de onvolkomenheid te beschouwen als het straks vermeld gevolg van het vrijhandelsstelsel, waarbij voor de invoeren meer en meer, en voor de uitvoeren bijna overal, de aanraking met den fiscus vervalt. Intusschen $z i j n$ er bij ons werkelijk leemten, die aangevuld, gebreken, die wellicht verholpen kunnen worden. Die welke het meest besproken werden, zijn tweeërlei. In de eerste plaats is de opmerking gemaakt, dat de waarde-opgave zooals die in de handelsstaten voorkomt, zeer van de werkelijkheid afwijkt, zoodat hetgeen van een bepaald artikel wordt gezegd ingevoerd te zijn, volstrekt niet overeenkomt met de geldelijke waarde welke dat artikel voor den handel vertegenwoordigt. Dat is het gewone gebrek van de zoogenaamde officieele waarde. Maar men vergete niet dat het opnemen dier officieele geldswaarde eigenlijk alleen geschiedt om van de zoo verschillende handelsartikelen de hoeveelheid op gelijkvormige wijze uittedrukken. Een totaalcijfer van den handelsomvang kan men alleen op deze wijze verkrijgen. Het zou toch onmogelijk zijn om hetgeen bij kilo's en bij hectoliters wordt aangegeven op andere wijze zamen te trekken. Wilde men een anderen weg volgen, en b. v. elke maand de juiste handelswaarde van elk artikel bij invoer en uitvoer opgeven, volgens den marktprijs van het ongenblik, men zou bevinden dat het, trots veol omslag en kosten, toch niet naar waarheid doenlijk zou zijn.

Voor den handelaar wien het on kennis van den juisten omzet in bepaalde artikelen te doen is, zou het ook geen voordeel aanbrengen; de in- en uitgevoercle hoeveelheden worden hem thans toch bekend, en welk geldbedrag die hoeveelheden naar de afwisselende marktwaarde in de maand vertegenwoordigen, kan hij, particulier handelaar, veel beter beoordeelen dan de regeering zou kumnen doen.

Dit wat betreft de opmerking aangaande de waarde.

Maar er is een ander bezwaar van gewicht, en dat ook door de Regeering wordt erkend. Dat bezwaar is o. a. gebleken bij Econ. Is93. 
de bespreking van het ontwerp-handelstractaat met Frankrijk; het is dat $b$. v. voor uitvoer naar eenig land alleen wordt opgegeven wat regstreeks naar dat land van bestemming gaat, zoodat, behalve voor de angrenzende landen, in den regel slechts wat van de zeehaven naar de andere gaat, als uitvoer naar dat bepaalde land wordt beschouwd. Evenzoo voor den invoer. Belgie, Duitschland en Engeland zijn alzoo verreweg de eerste landen wat onzen handel betreft. In werkelijkheid is dat ook wel zoo, doch niet in die mate als de haudelsstatistiek schijnt aan te geven. Onze handel met die landen directelijk heeft dien omvang niet. Ten gevolge der veelvuldige scheepsgelegenheid in Engeland te vinden, en bij het jaarlijks toenemend spoorwegverkeer dat ons over Duitschland en Belgie bereikt, is een deel van 't geen als onze handel met die drie landen voorkomt, als transit te beschouwen. Vele goederen moeten verder op, of kwamen van verder. Men weet nu niet wat transito is en het beeld dat de statistiek geeft van onzen handel met de verschillende rijken, is daardoor onvolledig. De Regeering heeft bij de behandeling van de laatste begrouting dit bezwaar erkend, en gesproken van de benoeming eener Commissie, zamengesteld zoowel uit mannen van de praktijk, als uit mannen van de wetenschap, ten einde een onderzoek in te stellen naar de wijze waarop hieromtrent eene voorziening zou kunnen getroffen worden.

Intusschen is een half jaar verloopen, en van het benoemen van die commissie heeft men niets vernomen. Nu meenen wij dat het op den weg van onze Vereeniging kan liggen om de Regeering daaraan te herinneren. Straks zal dan ook een voorstel gedaan worden om aan het Departement van Financien een adres te richten, houdende verzoek om aan dat voornemen gevolg te geven en eene betere inrichting van de handelstatistiek ter band te nemen

Dit wat de statistiek van de Regeering betreft.

Thans nog een kort woord omtrent hetgeen onze vereeniging in het laatst verloopen jaar gedaan heeft.

Het bestuur heeft het eerste deel van de „Jaarcijfers," dat gedrukt aan de leden is rondgedeeld en u, mijne Heeren, derhalve bekend is, uitgegeven.

Het tweede deel is ter perse en zal spoedig verschijnen; het is niet doenlijk geweest het vó́r deze vergadering gedrukt aan de leden te doen toekomen, daar ook eijfers van nog niet verschenen verslagen moeten opgenomen worden. Eene uitgave 
van de "Jaarcijfers" in het Fransch is in December Il. uitgekomen en, hoewel niet gedrukt in zulk een groot aantal exemplaren als de Hollandsche, aan die buitenlandsche bureaux en Vereenigingen toegezonden, met welle onze Vereeniging reeds sinds jaren in de gewone wisseling van stukken staat. Van alle zijden, mogen wij zeggen, zijn betuigingen van bijval ontvangen. Vooral is het uw bestuur aangenaam te vermelden dat zoowel van onze gezanten in den vreemde als van de buitenlandsche gezanten ten onzent veel instemming is ondervonden. Uit den grooten bundel brieven dienaangaande ontvangen, veroorloof ik mij een enkele mededeeling; o. a. wordt door het Italiaansche Statistisch Bureau gezegd.

"Il u'y " pas à douter" zoo schrijft ons dd. 12 Dec. de Hr. Luigi Bodio, Directeur der Statistiek anu bet Handels-ministerie te Rome, ,que ce trivail d'une utilité iudiscutable, vous assurera la recounaissance de cenx qui aiment ì étndier dans ses traits généranx, la constitution finincière, économique et morale de votre pays, ou qui diuss le but de faire des recherches plus particulières et plus détaillées, out besoin d'une indication exacte el suffisamment complète des sourees orirginelles.

On peut trouver injourd'hui moins regrettable qu'on ait supprimé daus le Royaume des Pars-Bas un Bureau de statistique générale, depuis que la société de statistiquc y supplée si bien par sou activité saviute.

Il est cependant certain que rotre publication réceute ra fourmir In preuve la plus solide de l'importance des résulfats qu'on pourxilt atteindre si on pourait restituer aux travaux de la statistique administrative dans votre pays une organisation métbodique et nuitaire."

De heer Levasseur te Parịjs, Professeur au Collège de France, schrijft ons 6 December:

„Il est regrettitble gu'un pays dont les affaires sont administrées très-régulièrement, et qui a eu le mérite de donner un des premiers en 1826, l'exemple de la création d'un Bureau Central et d'une Commission de Statistique, ait interrompu à cet égard sa tradition après lia mort du regretté monsieur Baunhauer, et c'est un houneur pour la Société de Statistique, d'avoir repris cette tradition par ses propres efforts, etc.

Ten slotte heb ik $u$ nog den bijval te vermelden welken deze publicatie der Verecniging bij onze regering heeft ondervonden. De Minister van Buitonlandsche zaken heeft in den aanrang des 
jaars de toezending van een dertigtal exemplaren ten behoeve onzer diplnmatieke en consulaire agenten verzocht, waaraan onzerzijds gaarne is voldaan. En zeer onlangs deelde de minister, bij missive van 4 April 1883 , ons twee brieven mede van den Nederlandschen Gezant te Petersburg, meldende 8/20 Maart:

.... „I $\mathrm{Ik}$ kau niet ualaten nijne ingenomenheid te betuigen met hedoeld hoogst belingrijk Statistisch werk, hetwelk de gelegevheid geeft om met een oogopslitg de meest naiuwkemrige gegevens te erlingen ontrent de Statistiek der takken van handel en nijverheid in Nederland, alsmede der instellingen die toi het Nederlindseh Stantsbestuur betrekking hebben.

Bovendien wordt door deze vitgave, wat het buitenland hetreft, in eene lang geroelde behoefte voorzien, diar gemis nan bekendheid met de Nederlandsche taal maar al te dikwijls oorzalk was, niet alleen dat onze Statistische Bescheiden buiten Nederland niet naar waarde op prijs gesteld, maar tevens zelden met vrucht konden worden geraadpleegd."

en in een latere missive 12-24 Mrart eene ruime toezending verzocht werd.

„Van verschillende kanten werd in de laatste dagen bij het Gezantschap anzoek gedaan om een exemplanr van dit hoogst belangrijk werk te bekomen; wel een hewijs, geloof $i k$, dat de waardeering welke ik de vrijheid wam ilan het slot van miju voormeld schrijven omtrent bedoeld Statistisch orerzicht wit te spreken, niet overdreveu was."

Mijne Heeren! Deze aanhaling uit de vele brieven van gezanten en Genootschappen ontvangen, waarvan ik u de verdere voorlezing zal besparen, moge $u$, evenals het Bestuur, de overtuiging geven dat wij niet te vergeefs hebben gewerkt, doch welligt iets helben mogen bijbrengen om ons vaderland en zijne laatste vorderingen op meer dan een gebied, in het buitenland naar waarde te doen schatten.

Thans rest mij $u$ te zeggen wat de voornemens van het Bestuur zijn aangaande het verder gebruik van het regeerings-subsidie.

Zooals gij weet, is het subsidic van $f 2,000$ 's jaars, - met uitzondering van het eerste jaar, toen wij nog niet goed op gang waren -, tot $\mathrm{nu}$ tos voortdurend besteed kunnen worden.

Dat subsidie wordt namelijk niet à forfait aan de Vereeniging gegeven, doch als restitutie voor gemaalite kosten. Om het subsidie te kunnen verkrijgen, moet dus elk jaar ten bedrage der verlangde som, arbeid verricht zijn. Van daar dat het sulısidie 
voor het eerste jaar niet ten volle verkregen is; het tweede jaar en vervolgens was dit echter het geval. Wij hebben nu als blijvende uitgave de njaarcijfers" die een gedeelte van het subsidie in aanspraak nam. De bedoeling is niet, daarvan elk jaar een overzicht in het Fransch te geven, 't geen op den duur te groote uitgaven zou vorderen; wellicht zou dat om de drie of vijf jaar voor ons in aanmerking kunnen komen, (tenzij dat b. v. het Departement van Buitenlandsche Zaken er voor de gezantschappen en consulaten zooveel prijs op mogt stellen, dat die Fransche uitgave door het Departement voor zijne rekening werd genomen). Bij de Vereeniging bestaat het voornemen niet die jaarlijks geregeld uit te geven.

Daarentegen heeft de Hoogleeraar van Pesch ons eene uitgave voorgesteld van door hem te bewerken verbeterde sterftetafelen, naar aanleiding der laatste volkstelling. $\mathrm{Na}$ bekomen inlichtingen van dien Hoogleernar heeft het Bestuur gemeend dat nuttig werk te moeten aanvaarden. De sterftetafelen, voor mannen en vrouwen afzonderlijk, zullen drieledig zijn:
a. voor groote gemeenten,
b. voor kleine gemeenten,
c. voor het geheele Rijk.

Arbeid en kosten voor deze zesderlei sterftetafelen zullen aanzienlijk zijn, zoodat wellicht in den eersten tijd, van het subsidie voor andere uitgaven weinig beschikbaar zal zijn, doch wij hebben gemeend, dat de voorgestelde, door een zoo uitnemend deskundige te leveren uitgave geheel op onzen weg lag, en ons daaraan niet te mogen onttrekken.

Met leedwezen moet ik aan de rergadering mededeelen het bericht van den heer van Pesch, dat treurige sterfgevallen in zijn gezin hem in de laatste dagen verhinderden te arbeiden, terwijl het nog wel eenigen tijd zal vorderen alvorens hij daartoe goed in staat zal zijn. Wij hopen en willen vertrouwen dat het uitstel niet van dien aard zal wezen, dat het ongebruikt blijven van een deel van het subsidie er het gevolg van zoude moeten zijn.

En hiermede Mijne Heeren, meen ik, onder dankbetuiging voor Uwe welwillende andacht, deze toespraak te mogen besluiten. Het Bestuur zal U weldra mededeelen wat het heeft gedaan om gevolg te geven aan het besluit der Vereeniging betreffende de oprichting van het Statistisch Instituut. Het onderwerp van een 
Centraal regeerings-bureau kan thans buiten bespreking blijven wegens den loop welke die zaak genomen heeft. Steeds blijf ik de oprichting van zoodanig goed georganiseerd Bureau ten onzent hoogst wenschelijk achten. Ook in Frankrịk werd weder onlangs op zeer goede gronden aangedrongen op meer wetenschappelijke centralisatie, als zeer goed met administratieve decentralisatie gepaard gaande. Bij dat al, ik herhaal het, moeten wij den toestand waarin wij verkeeren, goed voor oogen houden.

In 1860 benoemde de regeering eene Commissic onder voorzitterschap van den heer Ackersdijk, doch een votum der Tweede Kamer, den begrootingspost afstemmende, hief haar reeds spoedig op.

Later werd andermaal, op herhaald aandringen onzer vereeniging, eene poging aangewend door eene Regeering, van welke onze gewezen voorzitter, de heer Vissering, deel uitmaakte. Doch ook op dat regeeringsvoorstel weigerde de Kamer hare medewerking.

Nu zou ik meenen dat onze vereeniging voor cenigen tijd van verderen directon aandrang behoort af te zien. Ik geloof niet dat wij trachten moeten die deur, die ons op die wijze gesloten werd, te willen open rameien. Dat gaat niet. Waar het een loutere bestuurshandeling geldt, moge men zich goed gevolg voorstellen van een vernieuwd adres, bij afwisselend personeel of veranderde inzichten der regeering. Maar het zal moeilijk zijn tegenover herhaalde besluiten der vertegenwoordiging, de organiseering van een centraalbureau af te dwingen. De weg die naar mijne meening voor ons is aangewezen, is om door een degelijke en ruime opvatting onzer taak, de vertegenwoordiging gaandeweg met de statistiek te verzoenen; voort te gaan met bet. leveren en bewerken van bescheiden, die wel niet volkomen zijn, maar toch meer en meer gezuiverd worden van de gebreken in vorm en methode, die tot heden zoovelen van het gebruik er van weerhielden. Wij kunnen zoodoende an bet publiek, aan de pers en aan de leden van de vertegenwoordiging, door hen aan het gebruik van goede statistiek te gewennen, de overtuiging schenken van het voordeel en het gemak dat zij voor ieder burger oplevert en vooral voor hen, die aan de vaststelling der Staatsbegrooting en het raken van wetten deelnemen. Dàt is, mijns inziens, de weg welke door deze vereeniging thans het best kan worden gevolgd ter bereiking van haar doel, - een doel waaraan volstrekt niet te kort zal worden gedaan, al mogt door de oprichting van een Instituut, als waartoe uwe vergadering in beginsel besloten heeft, 
de werkkring onzer vereeniging intensiever worde dan tot heden plaats vond.

In elk geval mogen wij tot elkander zeggen: Onze zaak, nl. de Nederlandsche Statistiek, gaat vooruit, en daaraan zijn onze pogingen niet vreemd. $W_{i j}$ winnen telken jare eenig terrein. Onze wetenschap geeft licht, - al is dat nog niet electrisch! Laten wij er voor zorgen dat het althans zoo goed mogelijk zij, dan zal men van onze vereenigiiig kunnen zeggen: Vires acquirit eundo. 